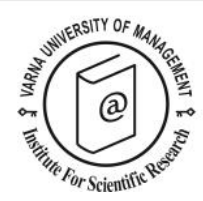

\title{
Spatial analysis of the relationship between tourist attractions and tourist flows in Turkey
}

\author{
Deniz Karagöz ${ }^{1^{*}}$, Semra Günay Aktaş ${ }^{2}$ and Yeliz Mert Kantar ${ }^{3}$
}

\author{
${ }^{1}$ Faculty of Tourism, Department of Tourism Management, Anadolu University, Turkey. E-mail: \\ dkaragoz@anadolu.edu.tr \\ ${ }^{2}$ Faculty of Tourism, Department of Tourism Management, Anadolu University Turkey. E-mail: \\ semragunay@anadolu.edu.tr \\ 3 Faculty of Science, Department of Statistics, Eskisehir Technical University, Turkey. E-mail: \\ ymert@eskisehir.edu.tr
}

${ }^{*}$ Corresponding author

\begin{abstract}
This study is intended to examine the relationship between tourist attractions (natural, cultural and historical) and tourist flows. In the study, secondary data for six provinces and 110 sub-provinces in the Southwestern Anatolia region of Turkey, visited by local and foreign tourists, are used. Four of these provinces have a coastline to the Aegean Sea and the Mediterranean. In this context, overnight data of tourists for 110 sub-provinces and the printed and online materials and overnight data of tourists are used to identify attractions. In this study, mapping analysis, local and global Moran's I, the classical regression and spatial regression models are benefited. Primarily, the spillover of attractions through maps and the distribution of tourist flows are presented in the study. When the relationship between tourist attractions and tourist flows are examined, the results of our analyses show that the Global Moran's I value is 0.25 and that those 110 sub-provinces could be similar in terms of tourist flow. It was determined whether there is a global clustering based on Global Moran's I value, and then the similar clusters, that is, similar sub-provinces in terms of tourist flow, were determined using the spectral clustering method. In addition, the neighborhood relationship and neighborhood interactions in terms of tourist flow are determined using local indicators of spatial analysis (LISA) alongside the Spectral Clustering Method. Finally, in the study field, the relationship between cultural, historical, and natural tourist attractions and tourist flow is explained using the classical regression model and the spatial regression model. The spatial-based models, especially the SEM, improve the model performance compared to the corresponding OLS model. In conclusion, it is found that there is a positive correlation between tourist flows and natural and historical attractions of the region, but a negative relationship between tourist flows and cultural attractions. Destination management implications are discussed.
\end{abstract}

Keywords: Tourist flows, attractions, exploratory spatial data analysis, spectral clustering, spatial regression analysis

Citation: Karagöz, D., Günay Aktaş, S. and Mert Kantar, Y. (2022). Spatial analysis of the relationship between tourist attractions and tourist flows in Turkey. European Journal of Tourism Research 31, 3102.

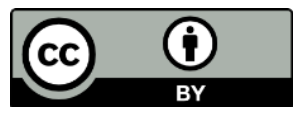




\section{Introduction}

The tourism sector is regarded as a source of economic growth, employment creation and export factor, particularly for developing countries, which hold $10.4 \%$ of the world's gross domestic product (GDP) (Kim, Chen, and Jang 2006; Porto, Garbero and Espinola, 2018). International tourism revenues reached US $\$ 1,448$ billion, with an increase of $4 \%$ in 2018. International tourist arrivals increased by $6 \%$ worldwide and reached 1.4 billion in 2018 (UNWTO, 2019). Before the COVID-19 outbreak, the number of international tourists was expected to reach 1.8 billion by 2030 (UNWTO, 2019). Although there is a significant pause in tourism because of this epidemic, tourism will recover, as in previous epidemics. The economic benefits of tourism have led to intense competition among destinations to get a greater share from tourism, in order that they can stay in the race. Therefore, the key factors are the attractions in the destinations and the number of tourists visiting such destinations (Dwyer and Kim, 2003; Murphy et al., 2000; Ritchie and Crouch, 1993, 2000).

Attractions are the fundamental tourism products of the destinations. Tourist destinations and levels of attraction are still important for tourism (Gunn, 1988; Lew, 1987). Tourist attractions are the core elements that support the development of local tourism. They provide the necessary recreational and entertainment opportunities to satisfy the basic travel motivations of visitors (Salazar, Chang and Girard, 2001). Consequently, attractions act as a key focus for tourism activities, which influences tourists' travel decisions. Furthermore, because of such critical importance, descriptive studies have been conducted since the 1970s, on the identification and the classification of tourist attractions, the assessment of the potential of tourist attractions in certain destinations, the perception of attraction by locals and tourists, and the spatial distribution of tourist flows and attractions. However, despite this important position held by tourist attractions (Jansen-Verbeke, 1985), studies to explain their relationship with tourist flows are limited. Investigating the impact of attractions (Salazar et al., 2001), a primary source of motivation, on the tourist flow to destinations, may provide important information for destination marketers at the planning stage of the destination and promotional activities. However, despite this important location of tourist attractions (Jansen-Verbeke, 1985), studies to explain their relationship with tourist flows are limited. Studying the relationship between tourist attractions and tourist flows can improve our knowledge of tourism policies and the spatial behavior of tourists. It is also necessary to investigate the spatial distribution of tourist flows for steady tourism growth across regions, because tourist flow shows whether resources, investment, and tourist activities are regulated in a balanced way (Yang and Wong, 2013). In addition, modeling spatially referenced tourist flows with tourism attractions, based on linear models, may produce inconsistent results in the presence of spatial effects or spatial dependence (spatial autocorrelation), as these spatial effects violate the basic assumptions of the linear model (Yıldırım \& Kantar, 2020). Therefore, tourist flows should be analyzed according to spatial statistics and spatial econometrics models. Given the above explanation, the aim of this study is to examine the relationship between tourist flows and tourist attractions (cultural, historical, and natural) in the region comprising six adjacent provinces and its 110 sub-provinces in Southwestern Anatolia, which attracts the most tourists in Turkey.

For this purpose, the spatial distribution of tourist flows and tourist attractions, and whether they form clusters or have any spatial dependence and interaction, are investigated. This was undertaken because the geographical variables are generally correlated. First, the global clusters were determined, based on Global Moran's I value, and then the local clusters, that is, the sub-provinces that are similar in terms of tourist flow were determined using the Spectral Clustering Method. The neighborhood interaction and spillover effect were determined by the local indicators spatial analysis (LISA) map. Since the tourist flow was found to have both local and global spatial autocorrelation, the relationship between the 
destination attractions and the tourist flow was examined using classical regression (OLS model) analysis and spatial regression analysis.

This study has two key contributions. First, this sub-province level study across six provinces of Turkey, located in the Aegean and Mediterranean Regions with the most intense tourist flow, ensures the appropriate determination of heterogeneity and variability throughout the provinces. By working on a sub-province level, more information and reliable findings can be obtained compared with studies conducted at urban and province levels. Second, it examines the relationship between tourist attraction and tourist flow using the spatial regression analysis, because spatial dependence violates the independence assumption of the OLS model. As a result, spatial models are convenient for studying this relationship.

The following sections of this article are organized as follows. First, a literature review on the variables of the research is included. Next, the methodology is discussed. The findings section includes findings related to the regression analyses where the relationships between spatial distribution, spatial clustering, and tourist flows and attractions is investigated. The conclusion section includes a discussion of the main findings of the study and recommendations for future studies.

\section{Literature review}

\section{Tourist attractions}

Tourist attractions are the core elements of tourism development for destinations and, therefore, they are among the most important factors supporting local tourism development. Attractions provide an important focus for tourism activities and influence tourists' travel decisions. Tourist attractions are "all those elements of a 'non-home' place that draw discretionary travelers away from their homes" (Lew, 1987, 554). Schmidt (1979) and Lew (1987) suggest that a region, space, or place can be defined as a tourist destination and attract tourists, if attractions and attributes exist. Attractions of a destination are considered as a component of the product bundle (Smith, 1994). Within this context, the attributes and attractions of a destination are inseparable. The tourism literature includes different definitions and classifications for attractions. Gunn (1988, 46-47) defines the attraction as an 'attraction magnetism' for a destination and suggests that the attraction force is true proof of the existence of a destination. Gunn $(1988,71)$ also describes natural and historical attributes as fundamental elements of destinationspecific attraction force. Burkart and Medlik $(1974,44)$ define it as tourist attractions or activity attractions having a magnetic influence on non-residents. Lundberg describes attraction as something that attracts tourists (1985: 33). According to Mac Cannell (1976), tourist attraction is an empirical relationship between tourist, landscape and marker. However, Gunn (1988) avoids using the word 'landscape' when defining and classifying attractiveness; he uses the word 'nucleus' instead. Similarly, Leiper (1990) agrees with this and uses the concept of nucleus as the central component of an attractiveness (Leiper, 1990). According to Gunn, an attraction consists of a combination of three functional parts; the 'nucleus', the 'inviolate belt', and the 'zone of closure'. Gunn gives the destination's wealth of historical values, its landscape, or its buildings as examples of the nucleus of a destination's attraction (Gunn, 1988).

Another approach to the classification of attractions in the literature is made by Lew (1987). Lew (1987) proposes three approaches to the classification of core elements; 'organizational', 'cognitive', and 'ideographic' perspectives. These three approaches constitute the basis for a comprehensive framework for typology and research of a tourist attraction (Lew, 1987). The organizational approach relates to the spatial and temporal relationships between attractions. The cognitive approach focuses on the demands of the tourists, namely the experiential aspects of the attractions. The ideographic approach is 
concerned with the defining qualities of destinations, in other words, the supply component of tourism. Attraction typologies focusing on the ideographic perspective define the concrete uniqueness of the destination rather than the abstract universal characteristics of a destination. These attractions are mostly used in studies investigating major destinations, such as the urbane ones. More detailed classification of Lew's ideographic attraction is made by Ferrario (1979), Gearing et al., (1974), Ritchie and Zins (1978), and Shih (1986). The typology of Ritchie \& Zins is a typical example of the conceptual approach. Attractions allow one destination to be compared with another (Lew, 1987). Ritchie and Zins (1978) classify the attractions of tourist attractions from a conceptual perspective. These are: natural beauty and climate; cultural and social characteristics; sports, recreation, and educational activities; shopping and commercial activities; infrastructure; price level; attitudes towards tourists; and lastly, accessibility. However, Lew states that the price level, attitude towards tourists, and accessibility are excluded from the conceptual classification, and that they should be included in the organizational and cognitive perspective rather than conceptual (Lew, 1987). In this study, the attraction, which is shown as a primary source of motivation in directing the tourist flow toward destinations, is classified based on Lew's ideographic approach. In this context, characteristics specific to destinations are defined and classified as destination attractions.

\section{Spatial Analyses in Tourism Studies}

Kreisel (2012) underlines the importance of spatial comprehension in tourism and leisure studies, for a holistic understanding of the phenomenon. In the tourism context, the spatial analyses-based studies can be typically examined under three groups. The first group comprises 'descriptive' studies, wherein the tourist profiles, the spatial attitudes, and the behavior of tourists are examined through spatial analyses. The second group comprises those in which the spatial distributions of tourists and accommodation enterprises within the tourism sector in certain destinations are examined using descriptive statistics (spatial correlation and mapping, and so on). The third group are those in which spatial econometric models are used.

In the tourism literature, there are many examples of descriptive studies wherein tourist behavior and categories are examined based on space. For example, Cooper (1981) describes the spatial behavior of tourists in the Channel Islands based on socio-economic variables and destination life cycle. Chadefaud (1981) creates a detailed map showing organized tourist groups and individual tourist activity areas in time and space. Debbage (1991) investigates the spatial behavior of tourists in the Bahamas. Montanari and Muscara (1995) identify nine tourist profiles for tourists arriving in Venice by temporal and spatial review based on travel characteristics, such as previous visits, length of stay, and purpose of visit. Wu and Carson (2016) use GIS to study multiple destination trip behavior of international and domestic tourists, in South Australia.

Studies that belong to the second group examine the spatial distribution of tourists and tourism enterprises. Chhetri et al., (2013) examine the spatial characteristics and clustering of tourism and accommodation employment. Based on clustering theory, they examine the general structure and composition of tourism in Australia and whether clusters exist within the framework of strategic economic areas and resource advantages. Using spatial autocorrelation measures, researchers identify regional accommodation in Victoria, Australia, in addition to five accommodation and tourism clusters. Zhang et al. (2011) investigate the spatial distribution of local and international tourists in 299 Chinese cities. Lu et al. (2011) examine the differences and importance of the distribution of tourists visiting cities in the Jiangsu region in China for the period 2001-2009 through global and local spatial autocorrelation analyses. The researchers state that the irregularity in the distribution of tourist arrivals point to an imbalance in tourism development because of the study. Yüncü et al., (2016) study the spatial 
dependence of domestic and foreign tourists coming to Turkey during the 2001-2013 period using the inverse distance weighted (IDW) mapping algorithm. The researchers find that international tourists are more concentrated in the southwest of Turkey's west coast, with domestic and foreign tourists found expanding into Turkey's central parts. Gunay Aktas et al., (2016), for the 2001-2013 period, investigate the occupancy rate in accommodation enterprises in Turkey using spatial analysis techniques. The researchers find differences in the spatial structure of local and foreign tourists' stays. In addition, Stankov et al. (2017) reveal the patterns and temporal changes of different spatial variables by spatial autocorrelation. The researchers find that international tourists are more concentrated in the southwest and west coast of Turkey, and that domestic and foreign tourists are expanding from the west to central Turkey. Gunay Aktas et al., (2016) investigate the occupancy rate in accommodation enterprises in Turkey using spatial analysis techniques for the 2001-2013 period. The researchers find differences in the spatial structure of local and foreign tourists' stays. In addition, Stankov et al. (2017) reveal patterns and temporal changes of different spatial variables by spatial autocorrelation.

The third group of studies use spatial models. Recently, there has been a gradual increase in empirical studies related to spatial econometrics in tourism research. For example, Lin et al., (2003) study the socio-economic predictors of the number of tourists in all tourist sites in Taiwan, using spatial regression models. Furthermore, Deller (2010) uses geographically weighted regression to model spatial variations in tourism and recreation's role in changing poverty rates in the US. Yang et al. (2011) base their research on spatial interaction theory. The researcher uses Wilson's model and spatial autocorrelation. The cities of the Anhui region in China are classified as developed, underdeveloped, less developed and undeveloped tourism cities due to spatial differences. Ma et al., (2015) examine the relationship between the development of tourism and the economic growth of the city during the 20022011 period, in 272 prefecture-level administrative units in China, by using panel data and spatial econometric analysis. Li et al., (2015) examine the environmental factors affecting hotel locations in Hong Kong. In their research, they map hotels and surrounding land use, attractions, and transportation facilities with a geographic information system. After that, they analyze the spatial relationships with a set of logistic regression models. Xing-Zhu and Qun (2014) use discovery spacetime analysis to study the tourist flow pattern during the 2000-2009 period. In addition, Li et al. (2016) investigate the function of tourism growth in reducing regional income disparity in China. Additionally, Yang and Fik (2014) examine the spatial effects of spatial spill over and heterogeneity on regional tourism growth. The researchers use a general spatial growth regression method, including spatial heterogeneity, to explain the spatial models of regional tourism growth rates (Yang and Fik, 2014). Lin et al., (2003) benefit from spatial regression models to examine whether the benefits of tourism development in Taiwan is distributed evenly over the geographical regions and socio-economic groups. In Shangai's tourist destinations, Shi et al. (2016) use spatial autocorrelation analysis to assess the relationship between crowding and popularity. After examining the panel data of regional tourism development in China, Luo et al. (2016) find that the urbanization level of the selected provinces has a positive effect on tourism development. Paci and Marrocu (2014) investigate the impact of local and international tourism on economic growth in 179 European regions. This is based on the spatial growth regression framework. Broekel and Alfken (2015) use spatial panel regression techniques, and determine that there is a negative relationship between wind turbines and tourism demand in cities close to the German coastline. In addition to spatial analysis, various regression methods have been applied to explain and predict tourists' length of stay (Santos, 2016; Van Berkel et al., 2014). 


\section{Methodology}

The study area

Six adjacent provinces, which are most popular among tourists, located in the Aegean and Mediterranean regions of Turkey in Southwestern Anatolia, were chosen as the study area. These provinces are Izmir, Mugla, Aydin, Denizli, Burdur, and Antalya (see Figure 1).

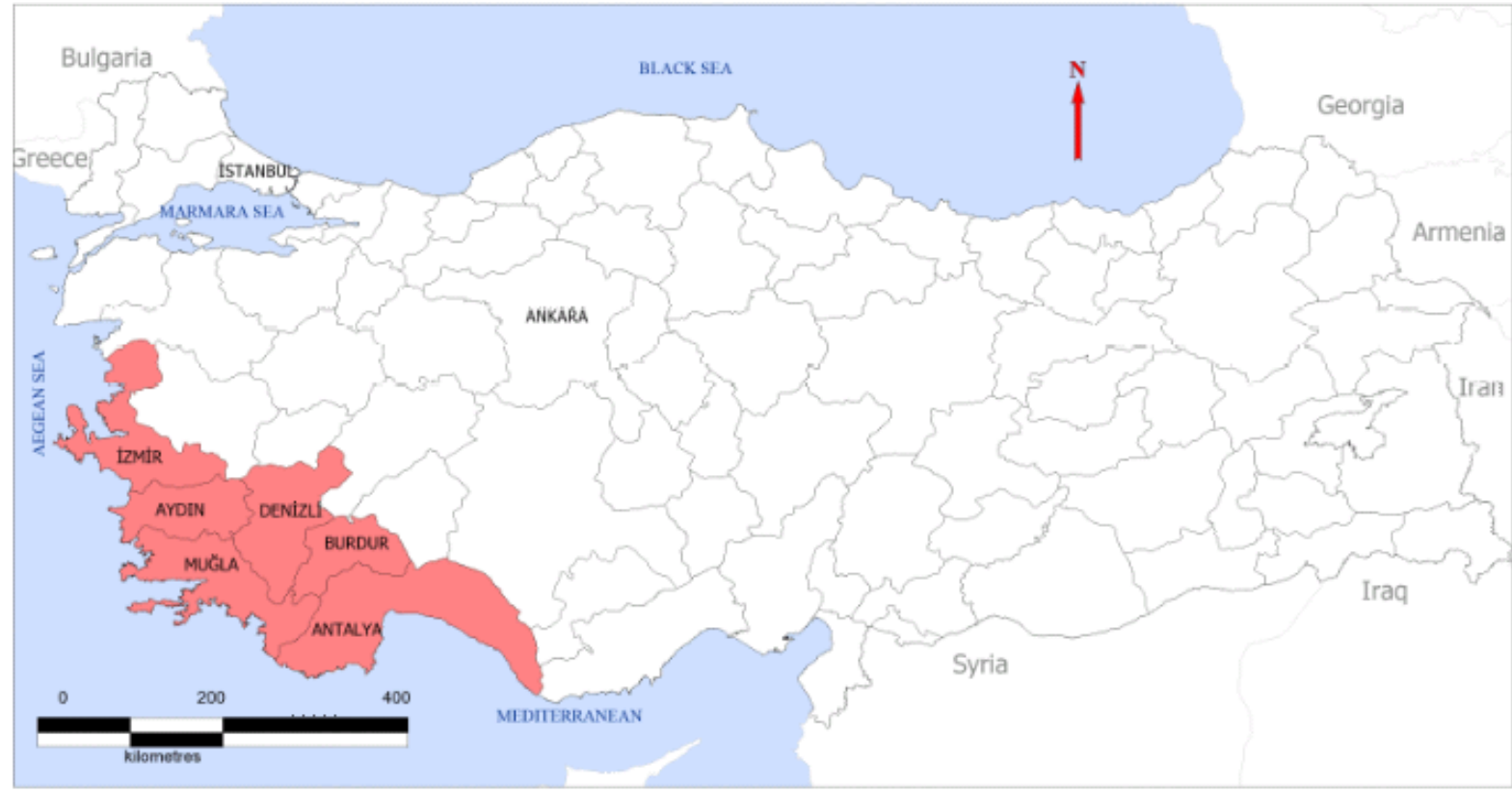

Figure 1. Geographical location of the study area

The study area attracts local and foreign tourists due to a favorable climate that results in an extended tourism season and diverse attractions in terms of natural and cultural heritage. The Antalya, Mugla, Izmir, and Aydin provinces are home to the most preferred tourism destinations in Turkey, and they hosted nineteen million tourists, according to data from 2017 (Table 1). In fact, the Mediterranean Region and Antalya province ranked first among those preferred by tourists traveling to Turkey. In addition, there is the high number of tourist arrivals, and average stay periods being relatively long. When overnight stays and average stay periods are examined, most tourists prefer to stay in facilities located in the Antalya province. This province has the longest overnight stay period averaging 5.1 days, followed by the Mugla province at 4.4 days. However, the average stay period in the Aydin province is above the national average at 3.5 days.

Table 1. Arrival of local and foreign tourist into facilities by 2017

\begin{tabular}{llll}
\hline Province & Domestic tourist & Foreign tourist & Total tourist \\
\hline Antalya & 3.813 .811 & 10.039 .062 & 13.852 .873 \\
Mugla & 1.046 .401 & 1.037 .246 & 2.083 .647 \\
Izmir & 1.452 .273 & 429.786 & 1.333 .552 \\
Aydin & 873.803 & 589.379 & 1.463 .182 \\
Denizli & 330.246 & 257.437 & 587.683 \\
Burdur & 28.215 & 1.624 & 29.839 \\
\hline
\end{tabular}




\section{Data}

In the study, secondary data has been collected to identify tourist attractions and to determine tourist flows. The Turkish Ministry of Culture and Tourism generates overnight stay statistics of tourists in Turkey, based on provinces and sub-provinces. Within this context, the 2017 overnight stay data for the Izmir, Mugla, Aydın, Denizli, Burdur, and Antalya provinces and 110 sub-provinces* have been obtained from this institution. Additionally, to identify the attractions in the provinces, secondary data has been collected from websites, tourism guide books, brochures and reports, projects, research articles, and theses related to this field, which have been prepared by governorships, municipalities, provincial culture and tourism directorates, and non-governmental organizations. For example, the Turkish Ministry of Culture and Tourism publications, the Turkish cultural assets inventory prepared for each province/sub-province by the Turkish Historical Society, cultural activity reports prepared by various NGOs, and natural assets prepared by environment institutions were examined. In addition, information was obtained from the tourism directorates of the provinces/sub-provinces in the study area to obtain information regarding various cultural events. Festivals that are no longer held, archeological sites, and museums that are closed to visitors were determined and removed from the data set. Lew's ideographic attraction classification, identifying the tangible individualities of a destination, has been taken as a basis for identifying attractions. For the study, tourist attractions are classified as cultural, natural, and historical attractions, based on Lew's classification. For example, while festivals, exhibitions, and art galleries were evaluated as cultural attractions, museums, historical sites, monuments, and historical buildings were evaluated as historical attractions. To ensure intercoder reliability, during the attractions' identification and coding, two researchers served as coders, independently examining and comparing the same materials, as recommended by Potter and LevineDonnerstein (1999, 273) and Krippendorff (2004, 414). Based on Lew's classification, attractions that overlapped in the investigations of both coders were included in this research. For example, one researcher evaluated a museum (Göreme open air museum, the ancient theatre of Side) as a historical attraction, whereas another researcher evaluated it as a cultural attraction. In such cases, the attractions were re-evaluated then added to the data set.

\section{Data analysis}

To understand the existence of spatial autocorrelation and spatial dependence in tourist flows within the study area in Turkey, maps, as well as Moran's I, which is the most widely-used quantitative measure of spatial autocorrelation, known as analogous to the Pearson's correlation, are used. Additionally, spectral clustering is a now a well-known method for clustering and is used to identify similar subprovincial groups in relation to the cultural, natural, historical attractions and tourist flows. In the final stage, a classical regression model as well as spatial regression models are conducted to identify the relationship between tourist flows and tourist attractions. MapInfo 17.2, SPSS and Geoda 1.12 software are used for all the analyses.

\section{Spatial autocorrelation analysis: Global Moran's I and Local Moran's I}

The Spatial Autocorrelation measures spatial autocorrelation or spatial dependence based on observations measured on locations. While spatial randomness indicates that observations at a given location do not depend on observations at neighbouring locations, spatial dependence creates a spatial pattern of observations. In positive spatial autocorrelation, it means that similar observation values occur in neighbourhoods, and in negative spatial autocorrelation, observations are different in neighbouring values (Scrucca, 2005). There are two types of spatial dependency that show the spatial relationship with respect to the whole region and the association of a single location with respect to the neighbourhood (Cliff and Ord, 1981; Anselin, 1995; Yildirim and Kantar, 2019, Lesage, 2009; Getis and Ord 1992; Getis and Aldstadt, 2004). 
The local measure of spatial autocorrelation determines deviations from global spatial relationship patterns and the presence of local clusters or local outliers (Boots, 2002). In this study, a spatial autocorrelation analysis was conducted to determine whether there is a spatial dependency in the study area with respect to the numbers of tourists which involves geographic location information.

\section{Spectral clustering}

Clustering is one of the most widely-used statistical methods and its aim is to divide data points into many sub-groups, such that while observations in the same group are similar, they are dissimilar to each other in different groups. Among clustering methods, spectral clustering (SC) (Fiedler, 1973) is a recent newly-developing method (Liu et al., 2014). SC employs spectral graph theory and linear algebra, as opposed to conventional clustering algorithms (Liu et al., 2014). To implement a spectral clustering method, similarity graph and eigenvectors of its Laplacian matrix should be computed; see (Liu et al. 2014; Jordan and Weiss, 2001) for computational details of SC.

\section{Spatial regression analysis}

In classical regression analysis, it is assumed that there is no spatial dependence when presenting the relationship model. However, if there is spatial dependence in the data, then it would be more appropriate to use spatial regression models instead of classical regression. Models with a spatially lagged variable are called spatial regression models. Spatially lagged variables provide spatial dependence in models as substance, in the sense that the dependent variable is influenced by the value dependent value for other countries, or the error term is influenced by its value for the region. Wellknown models are the spatial lag model (SLM) and the spatial error model (SEM) corresponding to spatially correlated dependent and error terms.

\section{Findings}

Mapping of attractions and tourist flows

In this study, a mapping analysis was performed to reveal the spatial spillover of tourist attractions and flows from 110 sub-provinces of six provinces. A thematic map showing the spatial spillover of the classified attractions in the study area was drawn (Figure 2). On the map, each province is distinguished by color, and sub-provinces are identified by lines. Historical attractions and cultural attractions are visualized with growing symbols, while natural attractions are visualized with green patterns according to the attractions' classification.

When Figure 2 is examined, it is noteworthy that the number of cultural attractions in Izmir are high in the sub-provinces with high population growth; this trend is seen in the sub-provinces within the Metropolitan Municipality and in other destinations. Therefore, Izmir is the cultural center of the Anatolian Peninsula (Akgüngör et al., 2017). In other provinces, cultural attractions are concentrated in their largest urban areas; that is, the central sub-province, because the primary goal of this attraction is to serve the residents of the urban area (Günay Aktaş and Baykal, 2016: 12). Owing to the nature of cultural attractions, they are expected to be greater in number in places where the population is dense and socioeconomic development levels are high (Aranburu et al., 2016). Furthermore, natural attractions are present in the sub-provinces of all the provinces. Moreover, the study area is also rich in terms of historical attractions. 


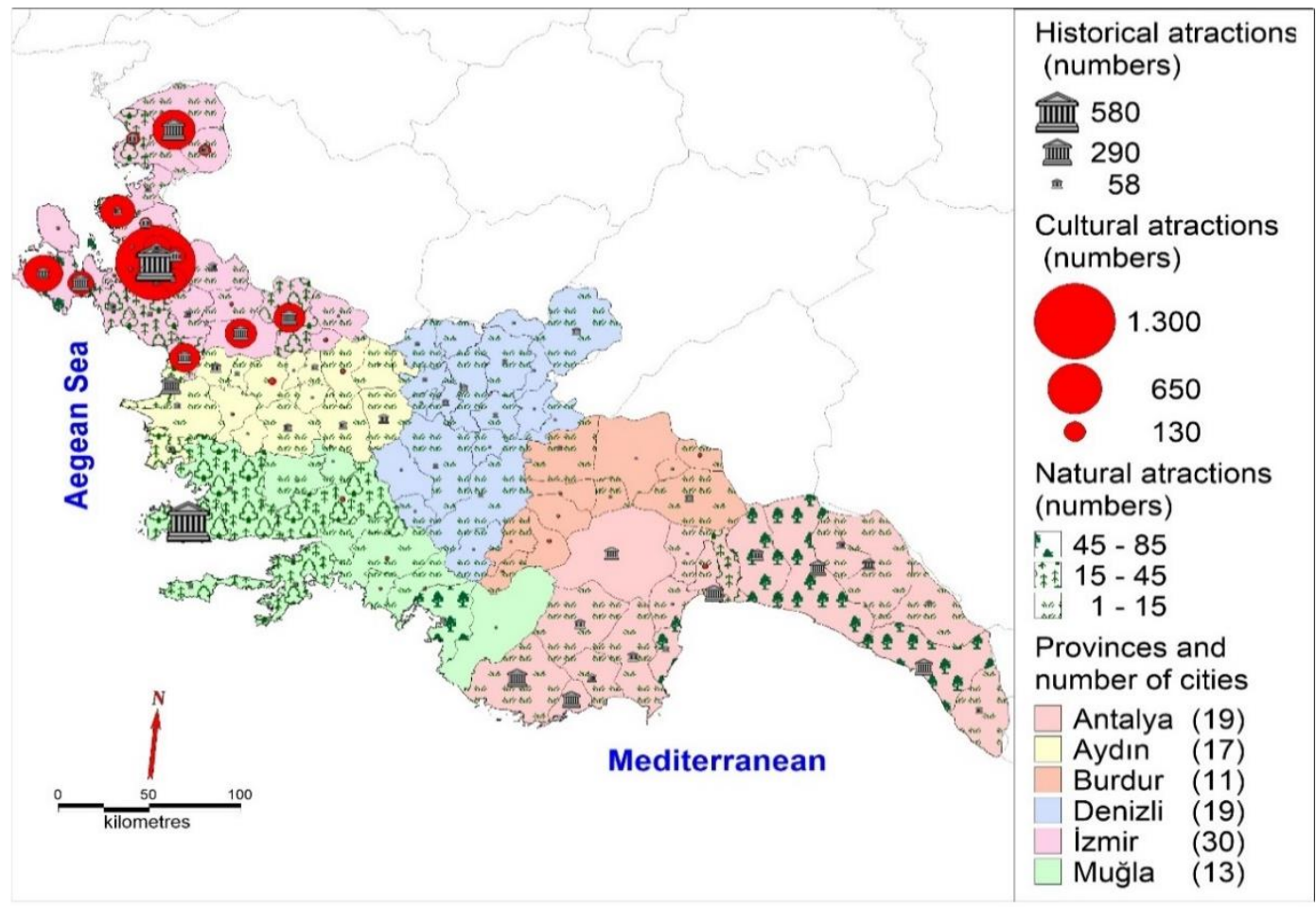

Figure 2. Distribution of tourist attractions

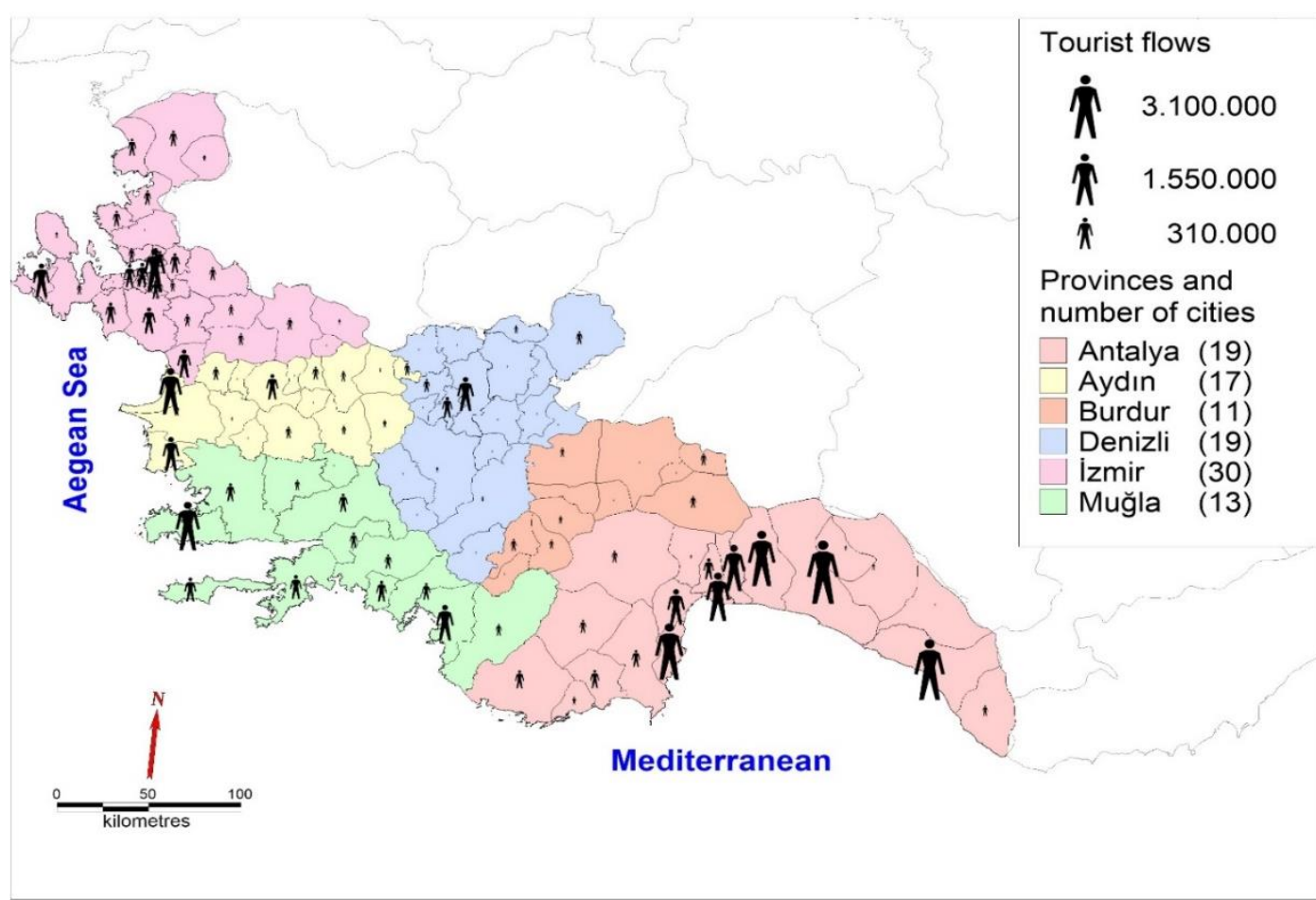

Figure 3. Distribution of tourist flows 
Figure 3 shows that the spatial spillover of tourists flows to the study area. The sub-province of Manavgat, Antalya, hosts the most tourists, with more than three million tourists per year. Out of the eight sub-provinces that host over one million tourists, the Bodrum and the Kusadasi sub-provinces are the sole representatives from Mugla and Aydin provinces, respectively; the others are in Antalya. Izmir's Konak sub-province, which is significant for urban tourism, serves nearly one million tourists. An increase in the number of tourists is noticed in the coastal sub-provinces of Antalya, in the east of the study area, in the coastal sub-provinces of Mugla and Aydin, in the north-west, and in the Metropolitan Municipality region in Izmir, except Cesme, Selcuk, and Menderes sub-provinces. Among the noncoastal sub-provinces, those that host a good number of tourists include the following: the Pamukkale sub-province of Denizli, known for its travertines and the Hierapolis Ancient City; the Merkezefendi sub-province, known for the Laodikeia ancient city; the Civril sub-province, known for its Natural Park; the Efeler sub-province of Aydin, known for the Tralleis Ancient City and Nasuh Pasa Social Complex. These destinations have advanced tourism infrastructure and superstructure and are a popular part of tour operators' itineraries.

\section{Spatial clustering of tourist flow}

The global spatial autocorrelation may be also seen in the map given in Fig.4; Moran's I value for the tourist flow. The Moran's I (Moran, 1950) is the widely-accepted autocorrelation measure, and it is used to measure such autocorrelations.

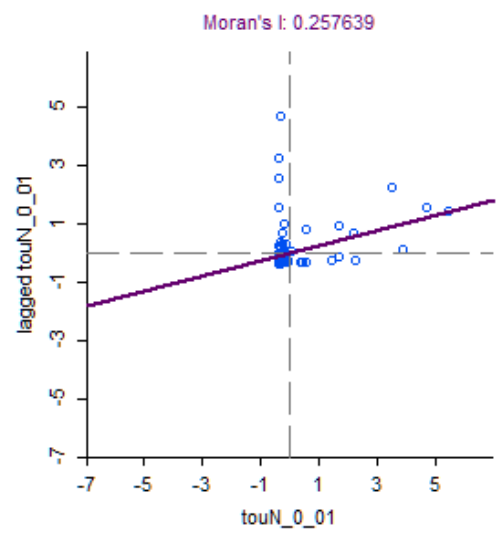

Figure 4. Moran's I value for the tourist flow

Moran's I scatter plot and value for the tourist flow is shown in Figure 4. It is found that the Moran's I value for tourists, 0.257639 , is significant and indicates a strong positive global spatial autocorrelation and, therefore, global clustering. In the present global spatial autocorrelation, the next step should be to discover the patterns of local spatial association (local spatial clustering). Therefore, we first consider spectral clustering (SC) to detect local clusters.

Fig.5. The spectral clustering map for provinces, in terms of tourist flow, provides the map obtained from SC in terms of the tourist flow for 110 sub-provinces. Fig. 6 illustrates the SC map in terms of the tourist flow together with cultural, natural, historical attractions. 

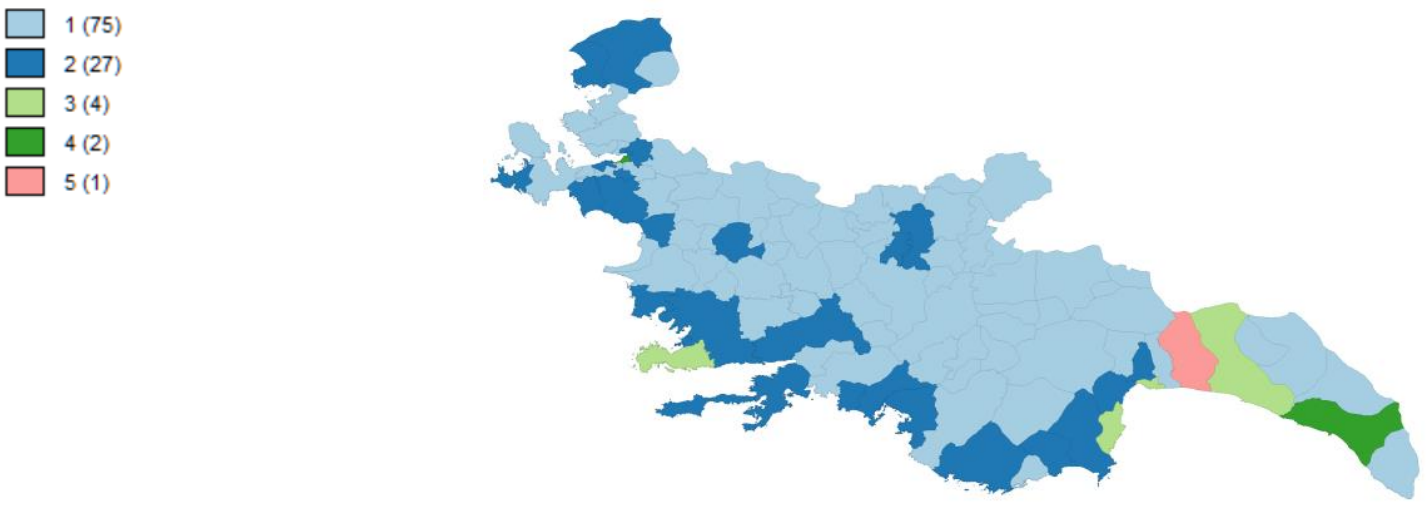

Figure 5. Spectral clustering map for provinces in terms of the tourist flow

When Figure 5 is examined, the tourist flow is more oriented toward the coastline in the study area. The sub-provinces of Antalya attract the highest tourist flow (the Serik, Alanya, and Kumluca and Manavgat sub-provinces have the highest, second highest, and the third highest tourist flows, respectively). The Bodrum sub-province of Mugla is included in the third group, with the highest tourist flow in this group. The tourist flow in the other coastal sub-provinces are classified under the fourth category. The Pamukkale and Efeler sub-provinces attract the same level of tourists in the coastal subprovinces.
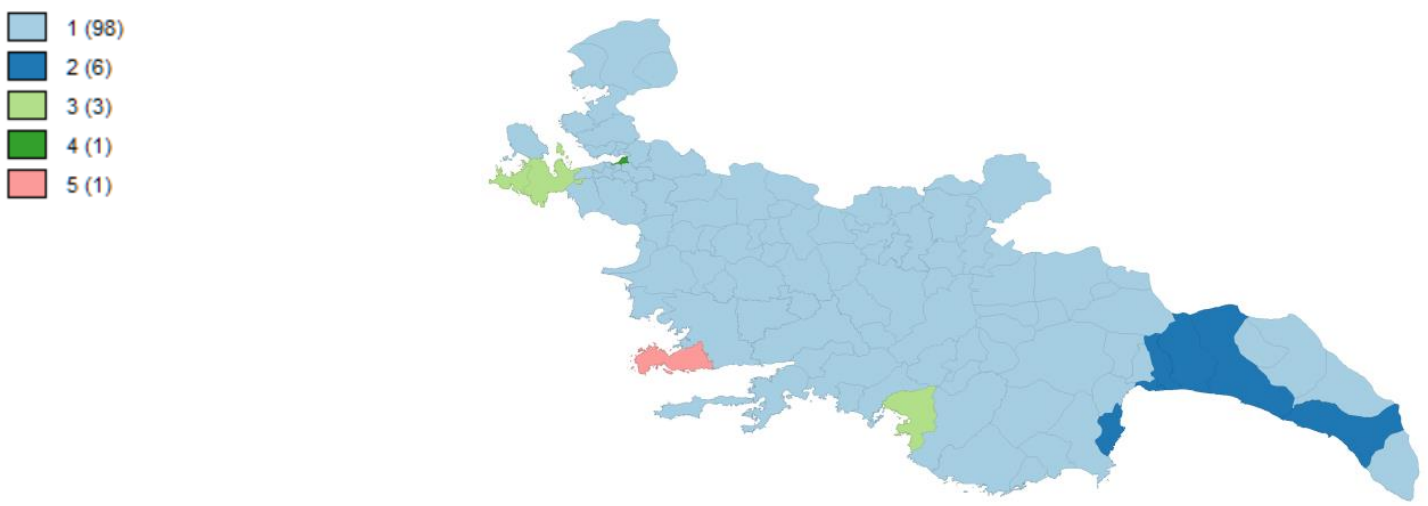

Figure 6. Spectral clustering map for provinces in terms of the tourist flow and cultural, natural, historical attractions

Because of SC, which was created by considering the attractions and the tourist flows, Bodrum, represented by a single group, is unique in the Mugla province. Cesme and Urla in the Izmir province share similar characteristics with Fethiye in Mugla. The Antalya province is seen to have the most similarities among the sub-provinces. Although the number of tourists in this province is high, the cultural attractions are less, as explained previously. 

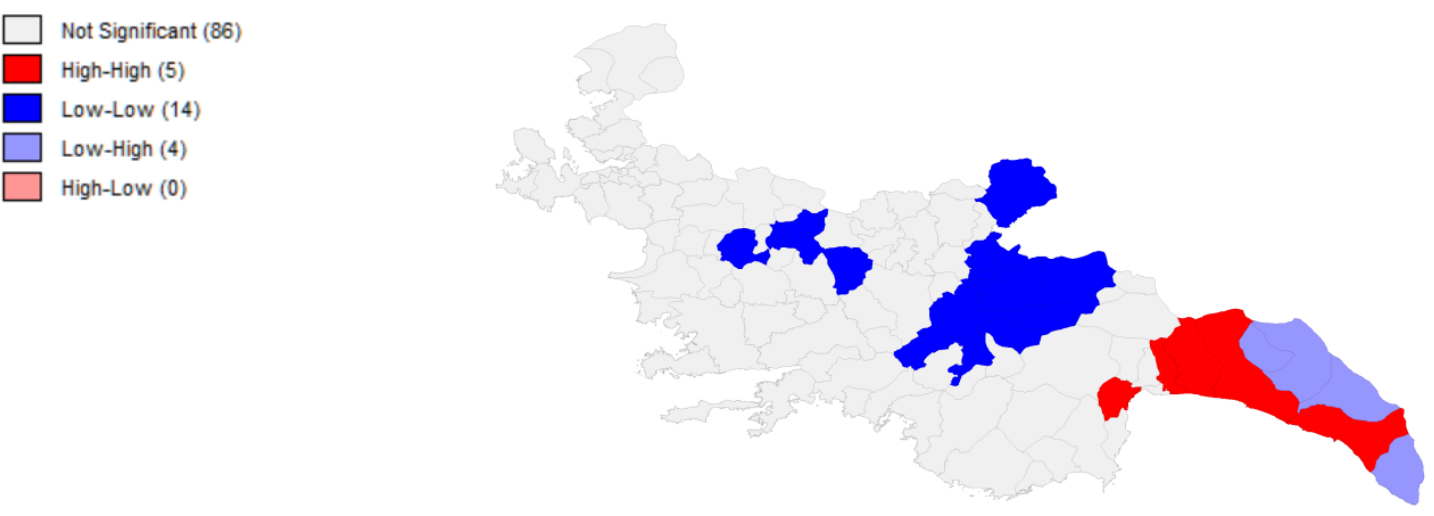

Figure 7. LISA for the tourist flow

The Lisa cluster, on the other hand, employs the local measure of spatial association (LISA), which is proportional to the Moran's statistic's (global) value. The maps of the LISA cluster indices (Fig.7. LISA for the tourist flow) are also used to display hot spots (High-High) and cold spots (Low-Low), in red and blue colors, respectively. These locations show that the variable's similar values are spatial clustered, meaning that the observed value is like its neighbors' value, demonstrating positive spatial autocorrelation. Other values' regions, High-Low and Low-High, are shown in pink and purple, respectively. Locations with Low-High and High-Low values indicate negative spatial relationships and potential spatial outliers on the map. A positive spatial neighboring association of High-High with the color red is observed in the coastal sub-provinces of Antalya; Low-Low sub-regions are seen in almost all parts of Burdur and in the interior parts of Aydin, as seen in Fig. 7. In addition, purple clusters can be found in Antalya's inner part, indicating that low values are surrounded by high values in Antalya's coastal sub-provinces.

\section{Relationship between tourist flow and destination's attraction}

The objective of this study is to determine the factors that affect the tourist flow in Izmir, Mugla, Aydın, Denizli, Burdur, and Antalya' sub-provinces. For this purpose, the cultural, natural, and historical attractions are considered as primary factors. First, classical the linear regression model (OLSM) with ordinary least squares (OLS) is used to demonstrate the statistical significance of the variables on the tourist flow, even if the data has geographic references. We have found $\mathrm{R}^{2}$ to be very low in the OLSM (Table 2). Moreover, the Jarque-Bera test indicates non-normality in errors and the Breusch-Pagan (377.728, p-value=o.ooo) and Koenker-Bassett (84.3451, p-value=o,ooo) tests show heteroscedasticity for errors by means of OLS residuals, which may be corrected by spatial models. Moreover, Moran's I for OLSM residuals is 0.3349 , showing significant positive autocorrelation in the residuals. In addition to the less fit, there are quite a few specification problems concerning regression assumptions. This indicates that the OLSM does not offer a good specification for modelling the tourist flow. Spatial autocorrelation is another issue for the OLSM when the error terms indicate certain spatial pattern where the combined spatial units display similar values than distanced units. In such cases, some widely-used spatial models include the spatial error model (SEM) and spatial lag model (SLM). 
Table 2. The classical linear model, spatial error model and spatial lag model for the tourist flow

\begin{tabular}{|c|c|c|c|c|c|c|c|c|}
\hline \multicolumn{9}{|c|}{ Coefficients and $p$-values } \\
\hline & $\begin{array}{l}\text { Spatial } \\
\text { Parameter }\end{array}$ & Slope & $\begin{array}{l}\text { Cultural } \\
\text { Attractions } \\
\left(\mathrm{X}_{1}\right)\end{array}$ & $\begin{array}{l}\text { Natural } \\
\text { Attractions } \\
\left(\mathrm{X}_{2}\right)\end{array}$ & $\begin{array}{l}\text { Historical } \\
\text { Attractions } \\
\left(\mathrm{X}_{3}\right)\end{array}$ & $\mathbf{R}^{2}$ & LOG & AIC \\
\hline OLS & - & $\begin{array}{l}-68884.5 \\
(0.09804)\end{array}$ & $\begin{array}{l}-734.7 \\
(0.01787)\end{array}$ & $\begin{array}{l}17508.1 \\
\text { (o.00ooo) }\end{array}$ & $\begin{array}{l}2435.87 \\
(0.00004)\end{array}$ & 0.532 & $-1545 \cdot 4$ & 3098.84 \\
\hline SEM & $\begin{array}{l}0.3436 \\
(0.0022)\end{array}$ & $\begin{array}{l}-64016.4 \\
(0.2152)\end{array}$ & $\begin{array}{l}-555.406 \\
(0.0485)\end{array}$ & $\begin{array}{l}17673.6 \\
\text { (o.0ooo) }\end{array}$ & $\begin{array}{l}2297.19 \\
(0.0000)\end{array}$ & 0,610 & -1538.61 & 3085.24 \\
\hline SLM & $\begin{array}{l}0.2323 \\
(0.0038)\end{array}$ & $\begin{array}{l}-100991 \\
(0.0110)\end{array}$ & $\begin{array}{l}-638.667 \\
(0.0254)\end{array}$ & $\begin{array}{l}16626 \\
(0.0000)\end{array}$ & $\begin{array}{l}2342.68 \\
(0.0000)\end{array}$ & 0.587 & -1540.92 & 3091.83 \\
\hline
\end{tabular}

All coefficients in the OLSM, SEM, and SLM are significant since the corresponding $p$-values are less than the significant level o.05. Here, we see that while the natural and historical attractions are associated with higher tourist flow, cultural attractions are negatively associated with tourist flow. Considering $\mathrm{R}^{2}$, LOG and AIC, the SEM is seen as a suitable model with significant spatial parameter, 0.3436 . The tourist flow is primarily explained with the natural attractions with the $R^{2}=0.53$, which is a large part of 0.61 . The estimated models are given as follows:

$$
\begin{aligned}
& Y=-68884.5-734.7 X_{1}+17508.1 X_{2}+2435.87 X_{3} \\
& Y=-64016.4-555.406 X_{1}+17673.6 X_{2}+2297.19 X_{3} \text { and } \lambda=0.3436 \\
& Y=0.2323 W Y-100991-638.667 X_{1}+16626 X_{2}+2342.68 X_{3}
\end{aligned}
$$

In all models, there is a positive significant relationship between tourist flow and variables, such as historical and natural attraction, whereas it has a negative significant relationship with cultural attractions. Moreover, we also find that the lagged-independent variables (neighboring region characteristics in terms of explanatory variables, cultural, natural, and historical attractions) do not affect explain the tourist flow.

\section{Conclusion}

The aim of this study is to investigate the relationship between the cultural, natural, and historical attractions of destinations and tourist flow. In addition, it was evaluated whether spatial regression performs better than linear regression in determining the relationship between tourist flow and tourist attraction.

First, cultural, natural, and historical attractions located in the provinces, at a sub-province level within the study area, were identified and classified. It was found that the tourist flow is not spatially homogeneous. It was determined that there is a positive correlation between the historical and natural attractions of the destinations and tourist flow. These findings are in line with previous studies. However, unlike previous studies, a negative relationship was found between the cultural attractions and tourist flow. Furthermore, it was determined that the cultural attractions are concentrated, specifically, in provincial centers where the population growth and the socio-cultural development level are high. The cultural attractions in central sub-provinces are a part of the urbanism for the residents in these regions. Compared with other destinations in the study area, these attractions are concentrated in areas where tourism enterprises and infrastructure are not prioritized, and where administrative, commercial, or industrial functions are prominent. This is consistent with the findings of a previous 
study by Aranburu et al. (2016), who state that the cultural attractions are inherently more prevalent in places with dense population and high levels of socio-economic development.

When the spatial spillover of tourist flow is examined, it is found that the spillover of tourist flow in the study area's provinces and sub-provinces is not balanced. Therefore, it is determined that the tourist flow is concentrated at certain points, but its expansion to the adjacent provinces and sub-provinces is not ensured. The spatial imbalance in tourism is also observed in several previous studies. Oppermann (1993), who examines the international travel flow in Malaysia, finds that a regional imbalance exists and that tourists are concentrated in the west coast of peninsular Malaysia. After examining the regional spillover of domestic and international tourists in Peru, O'Hare and Barret (1999) find that there is a spatial concentration and that it is not expanded to other areas. Similarly, Yang and Wong (2013), who examine the domestic and inbound tourist flows to Chinese urban areas, show that tourism flows are polarized into clusters. The researchers find that coastal areas and islands tend to be hot spots, as in other countries. Further, when the spatial clustering between tourist attractions and tourist flow is examined, the tourist flow is more oriented towards the coastline in the study area; this finding is like that of the current study. Although it is stated in general that urban areas that are adjacent to tourism centers (Cesme, Selcuk, Manavgat, Bodrum, Kemer, Serik, and others), such as hot spots, may benefit from the spillover's effect on tourism demand (Lue et al., 1993; Yang and Wong, 2012), the current study's findings do not show any such occurrences. Even in areas named as tourism provinces, such as the Antalya and Mugla provinces, it is found that the tourist flow is not homogeneous, and that it does not expand from destinations with the densest tourist flow to adjacent destinations.

Moreover, when the relationship between tourism attractions and tourist flow is examined in the present study, positive significant correlations are found between natural and historical attractions and tourist flow. However, a negative significant correlation is found between cultural attractions and tourist flow. Spatial concentration of tourist flow with this negative correlation can be explained with national tourism policies, risk aversion of tour operators, and the spatial concentration of tourism services (Gillmor, 1996; O'Hara and Barret, 1999). First, the duration of the tourists' stay is very short in the destinations with high concentration of cultural attractions and, it is possible in general, to define these tourists as same day visitors. Izmir, which is home to several cultural attractions, is used for the transition to the regions covering Kusadasi, Kemer, Alanya, and Bodrum, where the natural and historical attractions are densely located and where tour operators work intensely. Therefore, the destinations with high concentration cultural attractions are the transit points for domestic and foreign same day visitors. In addition, the tourism sector in Turkey is under pressure from foreign tour operators who specialize in packaged mass tourism and sea, sand and sun $(3 \mathrm{~S})$ tourism, and who avoid other tourism products to avoid risk. Consequently, they focus more on destinations, such as Bodrum, Alanya, Kemer, and Cesme, with a high concentration of natural and historical attractions, rather than cultural attractions.

In addition, we find that the relationship between tourist flow and natural attractions is higher than other attractions. This finding is an interesting result, because Turkey has rich historical attractions. However, as mentioned earlier, the fact is that sea-sand-sun tourism is the main tourism product and risk aversion can be explained as the reason for this result. Furthermore, it is fair to say that destinations with more historical attractions do not fully utilize the intercity spillover effects on tourists' flow and the competitive advantage from neighboring hot spot destinations.

The key significance of this research is in determining the relationship between tourist flows and destination attractions. Second, understanding the spillover of tourist flow and its relevance to 
attractions can help tourism policy-makers and marketers in developing tourism strategies and products and developing and improving tourist services. The spatial distribution of tourism flows is suggestive in developing strategies for tourism policies (Porto et al., 2018).

This research offers remarkable results for policymakers, tourism planners, marketing professionals, tourism managers, and other stakeholders. In the early periods of the five-year development plans, prepared for the improvement of tourism movements and sectors in Turkey, the need to concentrate the investments on southern and western coastal regions, with high tourist potential is emphasized to increase mass tourism and the number of foreign tourists (1963-1967). Additionally, the South Antalya Tourism Development Project (1976), covering the coastline of Antalya, where tourist flow is concentrated, aims to create the bed capacity to serve mass tourism and fulfill the accommodation needs of local and foreign tourists. However, currently, the aim is to recede from mass tourism, diversify the product, and to expand tourism throughout the country, in a balanced way. The findings of the study show that the tourist flow distribution within the study is imbalanced, and that the tourism effect is not expanded to destinations with high concentration of cultural attractions, located adjacent to those with intense tourist flow. The study also reveals a positive significant correlation between tourist attractions and natural and historical attractions, but a negative correlation between tourist attractions and cultural attractions. However, it would be possible to include destinations with high cultural attractions in the tourism sector, by focusing on specific tourism types, such as gastronomy, culture and cultural heritage tourism. The expansion effects of tourism demand should benefit through improvement of tourism services in the destinations that are adjacent to popular tourism centers, such as Alanya, Bodrum, and Kusadasi. Diversification of tourism products through multi-destination trips, including tourism centers and adjacent provinces and sub-provinces, would allow tourist flow to be distributed across a larger geographical area. Moreover, it will be important for destinations that are neighboring hot spot destinations, but which attract fewer tourists to collaborate with a hot spot area to gain a competitive advantage and to provide more tourist flow. Therefore, destination managers and marketers must establish a collaboration network, marketing alliances, and regional tourism associations between hot spot destinations and neighboring destinations.

The second key significance is that, when compared to the corresponding OLS model, spatial-based models, especially SEM, improve model efficiency. Spatial differences are not taken into account in studies conducted with traditional research models (Jin et al., 2019; Kim et al., 2020). In ordinary least squares (OLS) regression used in other studies, the dependent variable is assumed to be a linear function of the location and state factor. (Shabrina et al., 2020). However, spatial effects, such as spatial autocorrelation (spatial dependence) and spatial heterogeneity, are found when tourist attractions and tourist flows are referenced spatially, as in this study. These spatial effects violate OLS's basic assumptions of linearity and independence and covariance (Deller, 2010; Ponce et al., 2020; Santos \& Vieira, 2020). Spatial data analysis should be different from those used in non-spatial data analysis (Gilbert \& Chakraborty, 2011: 274). Therefore, it is recommended to use spatial models to determine the relationship between spatially dependent variables, such as tourism attractions, and tourist flow.

The present study has several limitations. This study examines the six provinces and 110 sub-provinces in Turkey and does not expand the research scope to include different provinces. Therefore, the representation and generalization of the results are limited. Although different destination types are preferred when choosing the research area, the determined tourist attractions are limited by the content analysis findings. As a further study, we will design the current work by expanding the regions in Turkey and consider the time and spatial effects together. The attractiveness model presented here should be 
tested in other regions. As a result, in future research, different environments will bring different attractiveness, and additional dimensions may be discovered.

\begin{abstract}
*The administrative fragmentation of Turkey includes 7 regions, 81 provinces, and 975 sub-provinces. Each province is divided into different numbers of sub-provinces, depending on its characteristics. TurkStat defines the largest settlement of each subprovince as urban, that is, there are several urban settlements in a province. The administrative functions of the sub-province centers cover all the settlements within the boundaries of the sub-province. The largest settlement of a province is regarded as the center of the province and has an administrative function covering the entire province. The largest urban settlements can be divided into several sub-provinces depending on population density to increase the accessibility of municipality services due to population density (such as Burdur and Mugla, located within the study area, having one central sub-province each, and the center of Denizli province having two sub-provinces). In a case where the population of the settlement in the center exceeds one million, it is managed by the Metropolitan Municipality to ensure coordination in municipal services (as in Izmir, Aydin, and Antalya, located within the study area).
\end{abstract}

\title{
References
}

Akgüngör, K., Kumral, N., \&Çelik, N. (2017). Ekonomik göstergeler ile İzmir (The Economic indicators for Izmir). https://www.egiad.org.tr/wp-content/uploads/arastirma-raporlari/ekonomik-demografikgostergelerle-izmir.pdf. (Accessed on 06.09.2019)

Alhemoud, A. M. \& Armstrong, E. G. (1996). Image of tourism attractions in Kuwait. Journal of Travel Research, 34(4), 73-76.

Anselin, L. (1988). Spatial econometrics: Methods and models. Dordrecht: Kluwer Academic.

Anselin, L. (1995) Local indicators of spatial association - LISA. Geographical Analysis, 27, 93-115.

Anselin, L. (2010). Thirty years of spatial econometrics. Papers in Regional Science, 89(1), 3-25.

Aranburu, I., Plaza, B., \& Estaban, M. (2016). Sustainable cultural tourism in urban destinations: Does space matter? Sustainability, 8(8), 699-706.

Baloglu, S. \& Brinberg, D. (1997). Affective images of tourism destinations. Journal of Travel Research, 35(4), 11-15.

BEBKA (2016). Bursa Eskișehir Bilecik Development Agency Official Site. http://www.bebka.org.tr/sitesayfa-16-bilecik.html?dUserLangAydi=2 (Accessed on 05.04.2019).

Brayley, R. E. (1990). An Analysis of destination attractiveness and the use of psychographics and demographics in segmentation of the within-state tourism market. Unpublished $\mathrm{PhD}$ thesis, Texas A\&M University, Texas, USA.

Broekel T., \& Alfken C. (2015). Gone with the wind? The impact of wind turbines on tourism demand. Energy Policy, 86, 506-519.

Burkart, A. J., \& Medlik, S. (1974). Tourism: Past, present and future. William Heinemann Ltd.

Çalışkan, U., Arikan Saltik, I., Ceylan, R. \& Nahar, O. (2019). Panel cointegration analysis of relationship between international trade and tourism: Case of Turkey and Silk Road countries. Tourism Management Perspectives, 31, 361-369.

Chadefaud, M. (1981). Lourdes: Un p'elerinage. Aix-en-Provence: une Ville Edisud.

Chhetri, A., Arrowsmith, C., Chhetri, P., \& Corcoran, J. (2013). Mapping spatial tourism and hospitality employment clusters: An application of spatial autocorrelation. Tourism Analysis, 18, 559-573.

Cliff, A. D., \& Ord, J. K. (1981). Spatial processes - models and applications. Pion, London.

Cooper, C. P. (1981). Spatial and temporal patterns of tourist behavior. Regional Studies, 15, 359-371.

Debbage, K. G. (1991). Spatial behaviour in a Bahamian resort. Annals of Tourism Research, 18, 251-268.

Deller S. (2010). Rural poverty, tourism and spatial heterogeneity. Annals of Tourism Research, 37(1), 180-205.

Durak S., Tupal Yeke S., \& Vural Arslan T. (2016). Significance of cultural heritage preservation in sustainable cultural tourism: Muradiye complex in Bursa, Turkey. European Journal of Sustainable Development 5(4), 1-12. 
Dwyer, L. \& Kim, C. (2003). Destination competitiveness and bilateral tourism flows between Australia and Korea. Journal of Tourism Studies, 14(2), 55-67.

Edwards, E., Griffin, T., \& Hayllar, B. (2008). Urban tourism research: developing an agenda. Annals of Tourism Research, 35(4), 1032-1052.

Ferrario, F. F. (1979). The evaluation of tourist resources: An applied methodology. Journal of Travel Research, 17(3), 18-22.

Fiedler, M. (1973). Algebraic connectivity of graphs. Czechoslovak Math. J., 23, 298-305.

Formica, S., \& Uysal, M. (2006). Destination attractiveness based on supply and demand evaluations: An analytical framework. Journal of Travel Research, 44, 418-430.

Gearing, C. E., Swart, W. \& Var, T. (1974). Establishing a measure of touristic attractiveness. Journal of Travel Research 12 (4), 1-8.

Getis, A. \& Aldstadt, J. (2004). Constructing the spatial weights matrix using a local statistic. Geographical Analysis, 36(2), 90-104.

Getis, A. \& Ord, K. J. (1992). The analysis of spatial association by means of distance statistics. Geographical Analysis, 24, 189-206.

Gillmor, D. A. (1996). Evolving air-charter tourism patterns: Change in outbound traffic from the Republic of Ireland. Tourism Management, 17(1), 9-16.

Günay Aktaş, S., Yüncü, D., \& Kantar, Y. M. (2017). Spatial distribution of occupancy rate in the hospitality sector in Turkey according to international and domestic tourist arrivals. In Saufi A., Andilolo I., Othman N., \& Lew, A. (Eds.), Balancing development and sustainability in tourism destination (pp.367-376). Singapore: Springer.

Gunn, C.A. (1988). Vacationscape: Designing tourist regions. (2nd Ed.), New York: Van Nostrand.

Jansen-Verbeke, M. (1985). Inner city leisure resources. Leisure Studies, 4(2), 141-157.

Kim, H.J., Chen, M., \& Jang, S. (2006). Tourism expansion and economic development: The case of Taiwan. Tourism Management, 27(5), 925-933.

Kreisel W. A. (2012). Some thoughts on the future research on leisure and tourism geography. Current Issues in Tourism, 15(4) 397-403.

Krippendorff, K. (2004). Reliability in content analysis. Some common misconceptions and recommendations. Human Communication Research, 30(3), 411-433.

Leiper, N. (1990). Tourist attraction systems. Annals of Tourism Research, 17, 379-81.

Lew, A. A. (1987). A Framework of tourist attraction research. Annals of Tourism Research, 14(4), 553575.

Li, H. Y., Chen J. L., Li, G., \& Goh, C. (2016). Tourism and regional income inequality: Evidence from China. Annals of Tourism Research, 58, 81-99.

Li, M., Fang L., Huang X., \& Goh, C. (2015). A spatial-temporal analysis of hotels in urban tourism destination. International Journal of Hospitality Management, 45, 34-43.

Lin, C. H., Morais, D. B. \& Hou, J. S. (2003). Case study of the relationship between socio-economic equality and spatial distribution of tourist sites in Taiwan: An application of geographic information systems (Report No. NE-317). Gen. Tech. Rep. NE-317. Newtown Square, PA: U.S. Department of Agriculture, Forest Service, Northeastern Research Station.

Liu, Y., Gao, X., Yan J., Han, S. \& Infield, D. G. (2014). Clustering methods of wind turbines and its application in short-term wind power forecasts. Journal of Renewable and Sustainable Energy, 6, o53119.

Lu, S., Zhang, J., \& Zhang, H. (2011). Spatial differential features of inbound tourists in Jiangsu, China. 19th International Conference on Geoinformatics (pp.1374-1377). Shanghai, China. Retrieved from http://ieeexplore.ieee.org/document/5980861/ (Accessed on 28.02.2019).

Lue, C. C., Crompton, J. L., \& Fesenmaier, D. R. (1993). Conceptualization of multi-destination pleasure trip decisions. Annals of Tourism Research, 20 (2), 289-301. 
Lundberg, D. (1985). The tourist business. New York: Van Nostrand Reinhold.

Luo J. M., Qiu H., \& Lam C. F. (2016) Urbanization impacts on regional tourism development: A case study in China. Current Issues in Tourism, 19 (3), 282-295.

Ma, T., Hong, T., \& Zhang, H. (2015). Tourism spatial spillover effects and urban economic growth. Journal of Business Research, 68(1), 74-80.

MacCannell, D. (1976). The tourist: A new theory of the leisure class. New York: Schocken Books.

McKercher, B., \& Lew, A. A. (2004). Tourist flows and the spatial distribution of tourists. Ed: Alan A. Lew, C. Michael Hall \& Allan M. Williams. A Companion to Tourism. Blackwell Publishing Ltd, pp.3648.

Montanari, A., \& Muscara, C. (1995). Evaluating tourist flows in historic cities: The case of Venice. Tijdschrift voor Economische en Sociale Geographie, 86, 80-87.

Moran, P. A. P. (1950). Notes on continuous stochastic phenomena. Biometrika, 37(1/2), 17-23.

Naude, W., \& Saayman, A. (2005). Determinants of tourist arrivals in Africa: A Panel data regression analysis. Tourism Economics 11, 3, 365-391.

O'Hare, G., \& Barrett, H. (1999). Regional inequalities in the Peruvian tourist industry. The Geographical Journal, 165(1): 47-61.

Oppermann, M. (1993). Tourism Space in developing countries. Annals of Tourism Research, 20(3), 535556.

Paci, R., \& Marrocu, E. (2014). Tourism and regional growth in Europe. Papers in Regional Science, 93(1), 25-50.

Porto, N., Garbero, N. \& Espinola, N. (2018). Spatial distribution of touristic flows in a gravity model in South America. Journal of Tourism Analysis: Revista de Análisis Turístico, 25(1), 39-53.

Potter, W. J., \& Levine-Donnerstein, D. (1999). Rethinking validity and reliability in content Analysis. Journal of Applied Communication Research, 27(3), 258-284.

Republic of Turkey Ministry of Culture and Tourism (2015). Accomodation statistics. Licenced by the ministry of culture and tourism. Republic of Turkey Ministry of Culture and Tourism, General Directorate of Investment and Enterprises. Retrieved from http://yigm.kulturturizm.gov.tr/ TR,9857/isletme-belgeli-tesisler.html (Accessed on 24.06.2019).

Ritchie, B. J. R., \& Zins, M. (1978). Culture as a determinant of the attractiveness of a tourist region. Annals of Tourism Research, 5(2), 252-67.

Ritchie, J. R. B., \& Crouch, G. I. (1993). Competitiveness in international tourism- A framework for understanding and analysis. Proceedings of the association internationale d'experts scientifiques du tourismue: Vol. 35. Competitiveness of Long Haul tourist destinations (pp. 23-71). St. Gallen: Niedermann Druck.

Ritchie, J. R. B., \& Crouch, G. I. (200o). The competitive destination, a sustainable perspective. Tourism Management, 21 (1), 1-7.

Salazar, J. P., Chang, S., \& Girard, T. C. (2001). Visitor sharing among country attractions and hotels. Journal of Hospitality \& Leisure Marketing, 8(1/2), 33-43.

Santos, G. E. O. (2016). An efficient method for modelling tourists' length of stay. Tourism Economics, $22(6), 1367-1379$.

Schmidt, C. (1979). The guided tour. Urban Life, 7, 4, 441-467.

Scrucca, L., 2005. Clustering multivariate spatial data based on local measures of spatial autocorrelation. Tech. Rep. 20. Università di Puglia.

Shi B., Zhao J., \& Chen P. (2016). Exploring urban tourism crowding in Shanghai via crowdsourcing geospatial data. Current Issues in Tourism, 20(11), 1186-1209.

Shih, D. (1986). VALS as a tool of tourism market research: The Pennsylvania experience. Journal of Travel Research, 24(4), 2-11. 
Shoval, N., \& Raveh, A. (2004). Categorization of tourist attractions and the modelling of tourist cities: based on the co-plot method of multivariate analysis. Tourism Management, 25(6), 741-750.

Smith, S. L. J. (1994). The tourism product. Annals of Tourism Research, 21(3), 582-595.

Stankov, U., Armenski, T., Klauco, M., Pavlukovic, V., Cimbaljevic, M., \& Drakulic-Kovacevic, N. (2017). Spatial autocorrelation analysis of tourist arrivals using municipal data: A Serbian example. Geographica Pannonica, 21(2), 106-114.

Tokay Argan, M. (2016). Eskișehir, Turkey as a crossroads for leisure, travel and entertainment. Cities, 56, 74-84.

Turkish Statistical Institute (TUIK) (2014). Seçilmiş Göstergelerle Bursa-2013. Ankara: TUIK, Publication No: 4210.

UNWTO (2019). World Tourism Barometer. 17(1), January. https://www.unwto.org/world-tourismbarometer-2019-nov (Accessed on 15.09.2019)

Van Berkel, D.B., Munroe, D. K., \& Gallemore, C. (2014). Spatial analysis of land suitability, hot-tub cabins and forest tourism in Appalachian Ohio. Applied Geography, 54, 139-148.

Vural Arslan, T. (2015). Developing a strategic approach for managing sustainable revitalisation in World Heritage Sites: Historical bazaar and Khans District, Bursa-Turkey. Archnet-IJAR: International Journal of Architectural Research, 9(1), 289-304.

$\mathrm{Wu}, \mathrm{C}$. L., \& Carson, D. (2008). Spatial and temporal tourist dispersal analysis in multiple destination travel. Journal of Travel Research, 46, 311-317.

Xing-Zhu, Y., \& Qun, W. (2014). Exploratory space-time analysis of inbound tourism flows to China cities. International Journal of Tourism Research, 16(3), 303-312.

Yang, C. H., Lin, H. L., \& Han, C. C. (2010). Analysis of international tourist arrivals in China: The role of world heritage sites. Tourism Management, 31(6), 827-837.

Yang, Y. \& Wong, K. K. F. (2012). A Spatial Econometric Approach to Model Spillover Effects in Tourism Flows. Journal of Travel Research, 51(6), 768-778.

Yang, Y., \& Wong, K. K. F. (2013). Spatial Distribution of Tourist Flows to China's Cities. Tourism Geographies. An International Journal of Tourism Space, Place and Environment, 15(2), 338-363.

Yang, Y., \& Fik, T. (2014). Spatial effects in regional tourism growth. Annals of Tourism Research, 46, 144-162.

Yang, Z., Lu, S., \& Jin, X. (2011). Tourism Spatial Association Analysis Based on GIS Technology for the Cities in Anhui of China. 19th International Conference on Geoinformatics (pp. 208-212), Shanghai, China. http://ieeexplore.ieee.org/document/5980861/ (Accessed on 28.02.2019).

Yüncü, D., Günay, S., Kantar, Y.M. (2017). Spatial relationship of tourist distribution in Turkey. In: Saufi A., Andilolo I., Othman N., \& Lew, A. (Eds) Balancing Development and Sustainability in Tourism Destinations (pp.353-365). Singapore: Springer.

Zhang, Y., Xu, J-H., \& Zhuang, P. (2011). The Spatial relationship of tourist distribution in Chinese cities. Tourism Geographies, 13(1), 75-90.

Received: 03/06/2020

Accepted: 20/04/2021

Coordinating editor: Basak Denizci 